\title{
SELECTIVE MOTOR NEURON DEATH AND HEAT SHOCK PROTEIN INDUCTION AFTER SPINAL CORD ISCHEMIA IN RABBITS
}

Masahiro Sakurai, $\mathrm{MD}^{\mathrm{a}}$

Masashi Aoki, MD ${ }^{\mathrm{b}}$

Koji Abe, MD $^{\text {b }}$

Mitsuaki Sadahiro, MD $^{a}$

Koichi Tabayashi, MD ${ }^{\mathrm{a}}$
Paraplegia is a serious complication that sometimes results from operation on the thoracic aorta. The mechanism of spinal cord injury has been thought to involve tissue ischemia, and spinal motor neurons are suggested to be vulnerable to ischemia. The exact mechanism, however, is not fully understood. To evaluate the mechanism of such vulnerability of motor neurons, we attempted to make a reproducible model for spinal cord ischemia and statistically analyzed cell damage. With this model, induction of heat shock protein 70 (HSP70) and heat shock cognate protein (HSC70) messenger ribonucleic acid molecules were investigated with Northern blot analysis for up to 7 days of reperfusion after 5 or 15 minutes of ischemia. Immunohistochemical studies of their proteins were also done. (heat shock proteins are a set of markers of neuronal injury after ischemia.) After 5 minutes of ischemia, there was no induction of HSP70 and HSC70 messenger ribonucleic acid molecules or their proteins, and all cells remained intact. In contrast, after 15 minutes of ischemia, HSP70 messenger ribonucleic acid was induced at 8 hours of reperfusion, and HSC70 messenger ribonucleic acid was expressed continuously at the control level. Immunoreactivity of HSP70 protein was slightly induced at 8 hours of reperfusion selectively in motor neurons, and about $70 \%$ of motor neuron cells showed selective cell death after 7 days of reperfusion. This study demonstrated induction of HSP70 messenger ribonucleic acid and its protein in motor neuron cells after transient ischemia in the spinal cord. This phenomenon was not accompanied by HSC70 induction. (J Thorac Cardiovase Surg 1997;113:159-64)
$S_{\text {tit }}^{\text {p }}$ inal cord injury after a successful operation on the thoracic aorta is a disastrous and unpredictable complication in human beings. In an attempt to prevent this complication, various methods of spinal cord protection have been suggested, ${ }^{1-3}$ including temporary shunts, partial bypass, and hypothermia. Regardless of the surgical technique or method of spinal cord protection used, no method has been developed that totally prevents the development of

From the Departments of Thoracic and Cardiovascular Surgery ${ }^{\mathrm{a}}$ and Neurology, ${ }^{\mathrm{b}}$ Tohoku University School of Medicine, Sendai, Japan.

Received for publication March 19, 1996; revisions requested May 8, 1996; revisions received July 18, 1996; accepted for publication July 22, 1996.

Address for reprints: Masahiro Sakurai, MD, Department of Thoracic and Cardiovascular Surgery, Tohoku University School of Medicine, 1-1 Seiryo-machi, Aoba-ku, Sendai 98077, Japan.

Copyright $(C) 1997$ by Mosby-Year Book, Inc.

$0022-5223 / 97 \$ 5.00+0 \quad \mathbf{1 2 / 1 / 7 6 8 2 8}$ paraplegia. ${ }^{4}$ The reported prevalence of paraplegia ranges from $0.9 \%$ to $40 \%$ in operations on the thoracic aorta. ${ }^{5,6}$

The mechanism of spinal cord injury during operations on the thoracic aorta is thought to be related primarily to direct tissue ischemia. Ischemia can occur because of permanent exclusion of the essential intercostal arterial blood supply to the spinal cord or by temporal interruption of the spinal cord blood flow. ${ }^{7,8}$ Spinal motor neurons are suggested to be more vulnerable to ischemia than dorsal horn neurons. However, the exact mechanism is not fully understood.

To evaluate the exact mechanism of such vulnerability of spinal motor neurons by ischemia, we attempted to make a reproducible model for spinal cord ischemia and statistically analyzed cell damage. Heat shock proteins (HSPs) are a set of proteins that are expressed ${ }^{9,10}$ at increased levels in cells subjected to a variety of stresses such as hyperthermia, ${ }^{11}$ trauma, ${ }^{12}$ and ischemia. ${ }^{13,14}$ Recent studies 
Table I. Neurologic scores at 2 days and 7 days after procedure

\begin{tabular}{ccccc}
\hline & & \multicolumn{2}{c}{$5 \mathrm{~min}$} & \multicolumn{2}{c}{15 min ischemia } \\
\cline { 4 - 5 } Animal & $\begin{array}{c}\text { Sham-operated ischemia } \\
\text { control (7 days) }\end{array}$ & $(7$ days) & 2 days & 7 days \\
\hline 1 & 5 & 5 & 5 & 2 \\
2 & 5 & 5 & 5 & 2 \\
3 & 5 & 5 & 5 & 3 \\
4 & 5 & 5 & 5 & 3 \\
5 & 5 & 5 & 4 & 2 \\
6 & & 5 & 4 & 3 \\
7 & & 5 & & 3 \\
8 & & 5 & & 2 \\
Means \pm SEM & $5 \pm 0^{*}$ & $5 \pm 0^{*}$ & $4.7 \pm 0.52 \dagger 2.5 \pm 0.52$
\end{tabular}

$S E M$, standard error of the mean.

${ }^{*} p<0.01$ compared with 7 days after procedure in 15-minute ischemia group.

$\ddagger p<0.05$ compared with 7 days after procedure in 15 -minute ischemia group.

have suggested that HSP70 and heat shock cognate protein (HSC) 70 are "molecular chaperones"15 that may be useful markers of neuronal injury after cerebral ischemia. ${ }^{16-18}$ Therefore we also examined changes of HSP70 and HSC70 messenger ribonucleic acid (mRNA) molecules and immunoreactivities of their proteins after spinal cord ischemia.

\section{Material and methods}

Animal models. Twenty-seven domesticated white rabbits (Japan) weighing 2 to $3 \mathrm{~kg}$ were used in this study and divided into three groups: a 5-minute ischemia group, a 15-minute ischemia group, and a sham-operated control group. Anesthesia was induced with intramuscular administration of ketamine at a dose of $50 \mathrm{mg} / \mathrm{kg}$ and maintained with $2 \%$ halothane inhalation. A $5 \mathrm{~F}$ pediatric balloon-tipped catheter (405, Braun, Melsungen, Germany) was inserted through a femoral artery and advanced $15 \mathrm{~cm}$ forward into the abdominal aorta. Preliminary investigations confirmed that the balloon in the distal end of the catheter was positioned 0.5 to $1.5 \mathrm{~cm}$ just distal to the left renal artery. During the experiment, aortic pressures were continuously monitored at both the proximal and distal positions of the balloon. Body temperature was monitored with a rectal thermistor and was maintained at $37^{\circ} \mathrm{C}$ with the aid of a heating pad during operation and subsequent ischemia.

Animals were allowed to recover at ambient temperature, and killed at 8 hours and 1,2, and 7 days after reperfusion ( $n=3$ at each time). In the sham-operated control group, animals were killed just after insertion of the catheter into the abdominal aorta without inflation of the balloon. Spinal cords were quickly removed immediately after death, with use of the plunger of a $1 \mathrm{ml}$ syringe. ${ }^{19}$ The tissue samples for RNA molecules were frozen in powdered dry ice and stored at $-80^{\circ} \mathrm{C}$. The samples for immunohistochemistry and histologic studies were fixed by immersion in $4 \%$ paraformaldehyde in 0.1 $\mathrm{mol} / \mathrm{L}$ phosphate buffer and then stored at $4^{\circ} \mathrm{C}$ for 1 week; they were then cut transversely at about the $\mathbf{L} 2$ or L3 level and, finally, embedded in paraffin.

In the experiment, rabbits were treated in accordance with the Declaration of Helsinki and the Guiding Principles in the Care and Use of Animals. Also, the experimental and animal care protocol was approved by the Animal Care Committee of the Tohoku University School of Medicine.

Neurologic assessment. Neurologic function was observed at 2 days and at 7 days after the procedure. Animals were classified according to a 5-point scale according to the method of Johnson, Kraimer, and Graeber ${ }^{20}$ as follows: 0 , hind-limb paralysis; 1 , severe paraparesis; 2, functional movement, no hop; 3 , ataxia, disconjugate hop; 4 minimal ataxia; and 5 , normal function. Two persons without knowledge of the treatment graded neurologic function independently. Statistical analyses of the neurologic score were done with the Mann-Whitney $U$ test.

Histologic study. The sections were stained with hematoxylin-eosin stain and examined by light microscopy. To determine the ischemic change, another series of animals was allowed to recover for 2 days after 15 minutes of ischemia $(n=6)$ and for 7 days after sham operation $(n=$ 5), 5 minutes of ischemia $(n=8)$, or 15 minutes of ischemia $(n=8)$. The spinal cords were removed, fixed by immersion in $4 \%$ paraformaldehyde in $0.1 \mathrm{~mol} / \mathrm{L}$ phosphate buffer for 7 days, and then embedded in paraffin. The number of intact motor neurons in the ventral gray matter region was counted. Statistical analyses for the cell numbers were done with the Mann-Whitney $U$ test.

Northern blot analyses. The inserts of cloned complementary deoxyribonucleic acid (pGA3 for HSP70, pGD3 for HSC70) selective for the HSP70 and HSC70 mRNA molecules, which were derived originally from cerebral cortex of gerbils, were $1.0 \mathrm{~kb}$ and $1.4 \mathrm{~kb}$, respectively. ${ }^{21}$ Total RNA molecules were extracted from spinal cords of sham-operated and postischemic rabbits, electrophoresed, and transferred to a nylon membrane according to our previous report. ${ }^{13}$ The probes were labeled with enhanced chemiluminescence (RPN3000, Amersham International, Buckinghamshire, United Kingdom) by direct labeling and hybridized against Northern blot membranes $(20 \mu \mathrm{g}$ of total RNA per lane) at $42^{\circ} \mathrm{C}$ for 20 hours in a hybridization solution containing formamide. After the hybridization, the filters were washed with $2 \times$ SSC $(1 \times$ $\mathrm{SSC}=150 \mathrm{mmol} / \mathrm{L} \mathrm{NaCl}+15 \mathrm{mmol} / \mathrm{L}$ sodium citrate) plus $0.4 \%$ sodium dodecyl sulfate at room temperature and then washed again with $1 \times$ SSC plus $0.4 \%$ sodium dodecyl sulfate at $42^{\circ} \mathrm{C}$. The filters were exposed to $\mathrm{x}$-ray film for 5 to 30 minutes at room temperature. $\alpha$-Tubulin mRNA was measured as an internal standard.

Histochemical study. Immunostaining against HSP70 and HSC70 in rabbit spinal cords was done according to our previous method ${ }^{22}$ with use of a kit (PK-6102 and PK-4010, respectively, Vector Laboratories, Burlingame, Calif.) with a mouse monoclonal antibody against HSP70 (RPN 1197, which was originally designed as clone C92; Amersham) and HSC73 (018-1551, which was originally designed as clone NT22; Wako, Osaka, Japan). Specificity of the antibody has been noted elsewhere. 23,24 

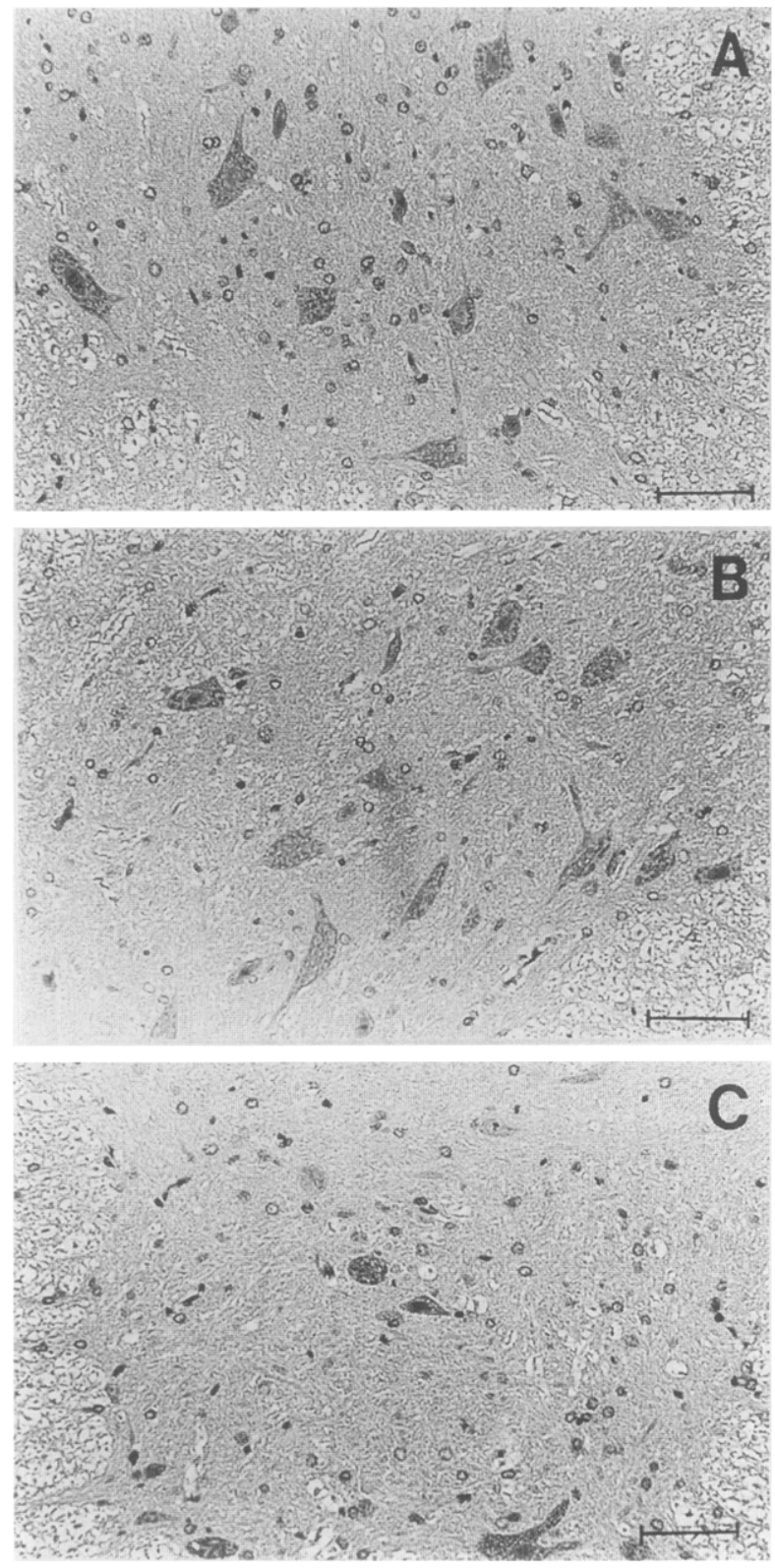

Fig. 1. Representative photographs of spinal cord sections stained with hematoxylin-eosin stain. There was no neuronal damage to any motor neuron cells in (A) shamoperated control group or (B) and 5-minute ischemia group. C, In 15-minute ischemia group, about $70 \%$ of motor neuron cells in Rexed's laminae VII, VIII, and IX were lost at 7 days of reperfusion. (Original magnification $\times 200$.)

\section{Results}

When the balloon of the catheter was inflated in the abdominal aorta, systemic blood pressure of the rabbits did not change. The arterial pressure distal to the inflated balloon fell to near zero and no

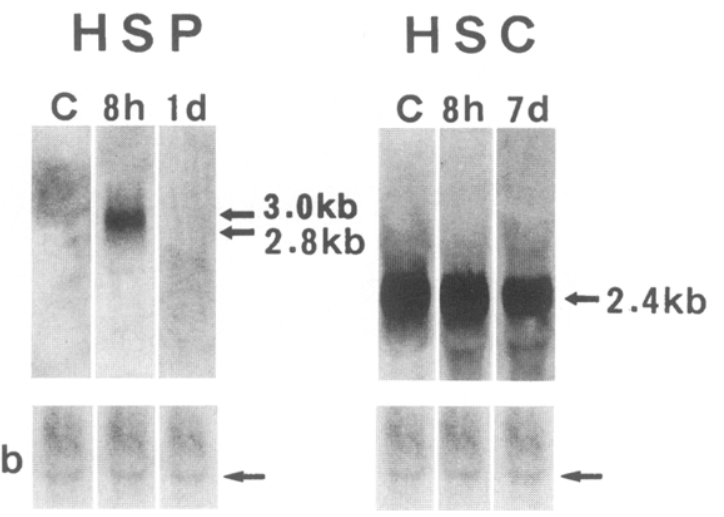

Fig. 2. Northern blot analysis of HSP70, HSC70, and tubulin $(T u b)$ mRNA molecules in rabbit spinal cord of sham-operated control group (C) and postischemic spinal cords at 8 hours, 1 day, and 7 days after reperfusion. Note that HSP70 and HSC70 probes detected different mRNA species in rabbit spinal cord and did not cross-react. Arrows show positions of detected HSP70 (2.8 kb and 3.0 $\mathrm{kb})$ and HSC70 (2.4 kb) mRNA molecules, respectively.

pulsation was recorded. On deflation of the balloon, systemic blood pressure of this portion decreased for 15 minutes and then returned to the normal level (data not shown). Spinal cord ischemia was achieved by the inflation of the balloon so as to obstruct blood flow to spinal cord. ${ }^{25,26}$

Neurologic outcome. The results are summarized in Table I. In the sham operation group $(n=5)$ and the 5-minute ischemia group $(n=8)$, all rabbits showed normal neurologic function (grade 5). In the 15-minute ischemia group at 2 days after the procedure $(n=6), 4$ rabbits $(67 \%)$ had normal findings (grade 5) and 2 rabbits (33\%) had minimal ataxia (grade 4). In the 15-minute ischemia group at 7 days after the procedure $(n=8), 4$ rabbits $(50 \%)$ did not hop (grade 2) and 4 rabbits (50\%) had ataxia (grade 3 ). There was a significant difference in the neurologic scores between 2 days after the procedure and 7 days after the procedure in the 15-minute ischemia group $(p<0.05)$. This difference was similarly marked between the 5-minute ischemia group and 15 -minute ischemia group at 7 days after the procedure $(p<0.01)$. Five minutes of ischemia did not affect neuronal function whereas 15 minutes of ischemia did affect such function.

Histologic study. Representative photographs of sections stained with hematoxylin-eosin stain are shown in Fig. 1. After 5 minutes of ischemia, no significant change was seen in motor neurons (Fig. $1, B)$ as compared with those in the sham-operated 

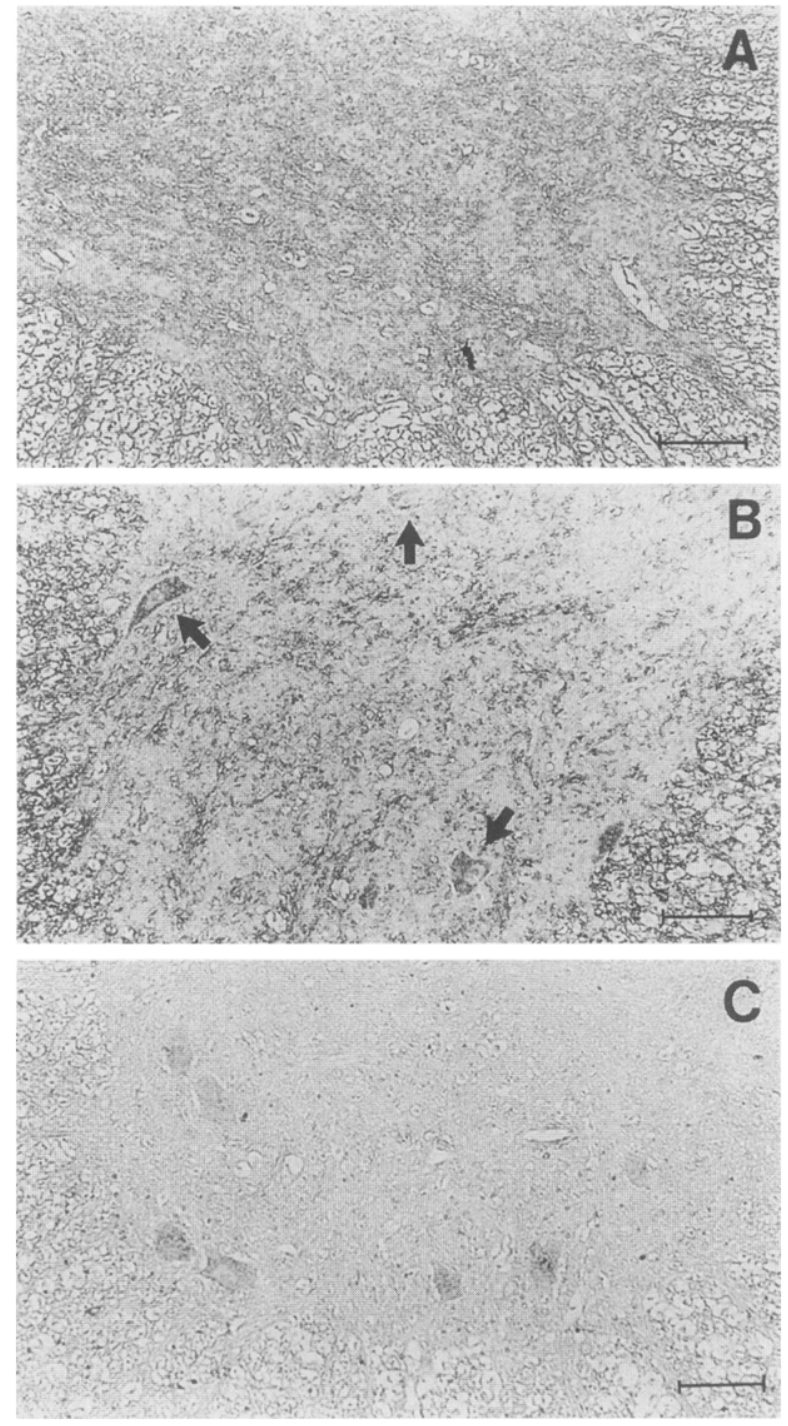

Fig. 3. Immunostaining against HSP70 in motor neuron cells (arrows) (A) in sham-operated spinal cord and (B) at 8 hours of reperfusion after 15 minutes of ischemia. C, Immunostaining against HSC70 in motor neuron cells at 8 hours of reperfusion after 15 minutes of ischemia. (Original magnification $\times 200$.)

control cases (Fig. 1, $A$ ). After 15 minutes of ischemia on day 7 of reperfusion, about $70 \%$ of motor neuron cells in Rexed's laminae VII, VIII, and IX were lost (Fig. 1,C), although most motor neuron cells remained intact after 2 days of reperfusion. Small motor neurons and intermediate neurons survived the ischemia (Fig. 1, C). Dorsal horn neurons were intact after 5 and 15 minutes of ischemia (data not shown). The results of cell counting in the ventral gray matter region on the paraffin
Table II. Numbers of large motor neurons in ventral gray matter at 2 days and 7 days after ischemia

\begin{tabular}{lccc}
\hline Treatment of animals & Day & $n$ & Cell numbers \\
\hline Sham & 7 & 5 & $24 \pm 1.8^{*}$ \\
Sham + 5 min ischemia & 7 & 8 & $23 \pm 1.4^{*}$ \\
Sham + 15 min ischemia & 2 & 6 & $20 \pm 1.9 \dagger$ \\
Sham + 15 min ischemia & 7 & 8 & $7 \pm 2.1$ \\
\hline
\end{tabular}

Values are means \pm standard error of the mean.

${ }^{*} p<0.01$ compared with 7 days after procedure in 15 -minute ischemia group.

$\dagger p<0.05$ compared with 7 days after procedure in 15 -minute ischemia group.

Table III. Signal intensities of Northern blot analysis of HSP70 and HSC70 $\mathrm{mRNA}$ and staining for immunoreactive HSP70 and HSC70 proteins after 15 minutes of ischemia

\begin{tabular}{cccccc}
\hline & \multicolumn{2}{c}{ HSP70 } & & \multicolumn{2}{c}{ HSC70 } \\
\cline { 2 - 3 } \cline { 5 - 6 } Time course & $m R N A$ & Protein & & $m R N A$ & Protein \\
\hline Sham & --- & -- & ++++++ & +++ \\
8 hr & +++ & ++++++ & ++++++ & +++ \\
1 days & --- & --- & ++++++ & +++ \\
2 days & --- & --- & ++++++ & +++ \\
7 days & -- & --- & ++++++ & +++ \\
\hline
\end{tabular}

sections obtained from another series of animals are shown in Table II. Five minutes of ischemia did not affect the number of motor neuron cells in contrast to motor neuronal loss in the group subjected to 15 minutes of ischemia at 7 days after the procedure.

Northern blot analyses. Fig. 2 shows the results of Northern blot analysis with cloned HSP70 and HSC70 complementary deoxyribonucleic acid probes. In the spinal cords of sham-operated animals, there was no hybridization with the HSP70 mRNA whereas HSC70 mRNA was normally expressed. After 5 minutes of ischemia, HSP70 mRNA was not induced at any time (data not shown). After 15 minutes of ischemia, HSP70 mRNA was induced only at 8 hours of reperfusion, and the amount of HSP70 mRNA returned to the sham-operated control level by day 1 (Fig. 2, left; Table III). The level of HSC70 mRNA was expressed at all times after 5 and 15 minutes of ischemia (Fig. 2, right; Table III).

Histochemical study. Photographs for immunoreactive HSP70 and HSC70 in sections from spinal cords are shown in Fig. 3. The spinal cords of sham-operated animals did not show HSP70 immunoreactivity in any cells (Fig. 3, A; Table III). 
Although no cells in the spinal cord produced an immunoreactive HSP70 at any time after 5 minutes of ischemia, motor neurons selectively showed a moderate immunoreactivity for HSP70 at 8 hours of reperfusion after 15 minutes of ischemia (Fig. 3, $B$, arrows; Table III). Other cells in the spinal cord did not express immunoreactive HSP70. Immunoreactivity for HSC70 was evident in motor neuron cells in sham-operated animals, but showed no change after 5 or 15 minutes of ischemia (Fig. 3, C; Table III) as was the case with mRNA (Fig. 2, right).

\section{Discussion}

We have demonstrated selective motor neuron death in lumbar regions of the rabbit spinal cord with a reproducible model. The spinal cord ischemia model that uses balloon catheters has a number of advantages in comparison with other models of spinal cord ischemia. ${ }^{25,27}$ First, the anatomy of the rabbit is simple in comparison with that of other animals such as the dog and the cat. Balloon occlusion of the abdominal aorta is simple, quickly accomplished, and less invasive than conventional methods of ligating the aorta by laparotomy. Therefore postoperative complications were minimal and functional deficits were stereotypical. The neurologic and histologic patterns of 5 and 15 minutes of ischemia in our models are very much reproducible. Northern blot analyses were also reproducible at each point (Table III). This is the first quantitative study in which surviving motor neuron cells have been counted after spinal cord ischemia.

Fifteen minutes of ischemia is a relatively short ischemic period in comparison with those used in previously reported models, ${ }^{20}$ and after the ischemia, selective motor neuron damage was observed after only 7 days of reperfusion in this model. This phenomenon is known as selective neuronal death in motor neuron cells after spinal cord ischemia. ${ }^{28}$ This result is compatible with delayed deterioration of neurologic function after spinal cord ischemia. In addition, this result shows that motor neurons are most vulnerable to ischemic injury. A previous report showed that there are no differences in spinal blood flow between ventral and intermediate gray matter after transient ischemia. ${ }^{29}$

It is known that HSP70 and HSC70 proteins bind denatured or unfolded proteins and degrade or refold the abnormal proteins during stressful conditions. Recent studies have suggested that HSP70 and HSC70 mRNA molecules should be useful markers of neuronal injury after cerebral isch- emia. ${ }^{16-18}$ We previously showed that HSP70 mRNA would be induced by stress stronger than that which eventually leads to cell death. The selective induction of HSP70 mRNA and protein in motor neuron cells may indicate a stress response that occurs in the spinal cord after 15 minutes of ischemia and, finally, about $70 \%$ of motor neurons were selectively damaged after 7 days of reperfusion. In addition, with regard to the stress of hyperthermia, induction of HSP70 was observed in glial cells rather than in motor neurons in the rabbit spinal cord. ${ }^{30}$ Thus our results suggest that a different mechanism of stress response may be present between hyperthermia and ischemia in the rabbit spinal cord.

In the rat or gerbil brain, HSC70 mRNA was induced in slight ischemia, which causes neither HSP70 mRNA induction nor cell death. ${ }^{16,18} \mathrm{Al}-$ though HSP70, as a stress-inducible protein, may have a protective role in stressful cellular events, it may also serve as a marker of such stress, energy failure, cold injury, and ischemia. Therefore this dissociation of induction of HSP70 and HSC70 mRNA serves as a useful biochemical marker for neuronal damage after cerebral ischemia. ${ }^{16}$ However, HSC70 mRNA and protein were continuously expressed at the control level in rabbit motor neuron cells after 5 and 15 minutes of ischemia. Therefore the mechanisms of cell injury of the motor neurons in the spinal cord and the hippocampal cells of the brain after ischemia might differ.

This study demonstrated induction of HSP70 mRNA and its protein in motor neuron cells after transient ischemia in the spinal cord. This phenomenon was not accompanied by HSC70 induction.

We thank J. Suzuki for his excellent technical assistance and M. Watanabe for helpful discussion.

\section{REFERENCES}

1. Symbas PN, Pfaender LM, Drucker MH, Lester JL, Gravanis $\mathrm{MB}$, Zacharopoulos $\mathrm{L}$. Crossclamping of the descending aorta: hemodynamic and neurohumoral effects. $J$ Thorac Cardiovasc Surg 1983;85:300-5.

2. Svesson LG, Rickards E, Coull A, Rogers G, Fimmel CJ, Hinder RA. Relationship of spinal cord blood flow to vascular anatomy during thoracic aortic cross-clamping and shunting. J Thorac Cardivasc Surg 1986;91:71-8.

3. Pontius RG, Brockman HL, Hardy EG, Cooley DA, DeBakey ME. The use of hypothermia on the prevention of paraplegia following temporary aortic occlusion: experimental observations. Surgery 1954;36:33-8.

4. Grossi EA, Krieger KH, Cunningham JN Jr, Culliford AT, Nathan IM, Spencer FC. Venoarterial bypass: a technique 
for spinal cord protection. J Thorac Cardiovasc Surg 1985; $89: 228-34$.

5. Crawford ES, Waler HS, Saleh SA, Normann NA. Graft replacement of aneurysm in descending thoracic aorta: results without shunting. Surgery 1981;89:73-85.

6. Crawford ES, Crawford JL, Safi HJ, Coselli JS, Hess KR, Brooks B. Thoracoabdominal aortic aneurysms: preoperative and intraoperative factors determining immediate and longterm results of operations in 605 patients. J Vasc Surg 1986;3:389-404.

7. Kats NM, Blackstone EH, Kirklin JW, Karp RB. Incremental risk factors for spinal cord injury following operation for acute aortic transection. J Thorac Cardiovasc Surg 1981;81: 669-74.

8. Livesay JJ, Cooley DA, Ventemiglia RA, et al. Surgical experience in descending thoracic aneurysmectomy with and without adjuncts to avoid ischemia. Ann Thorac Surg 1985;39:37-46.

9. Bienz M, Pelham HRB. Mechanism of heat shock gene activation in higher eukaryotes. Adv Genet 1987;24:31-72.

10. Lindquist S. The heat shock response. Ann Rev Biochem 1986;55:1151-91.

11. Currie RW, White FP. Trauma induced protein in rat tissues: a physiological role for "heat shock" protein? Science 1981; 214:72-3.

12. Brown IR, Rush S, Ivy GO. Induction of a heat shock gene at the site of tissue injury in the rat brain. Neuron 1989;2:155964.

13. Abe K, Tanzi RE, Kogure K. Induction of HSP70 mRNA after transient ischemia in gerbil brain. Neurosci Lett 1991; 125:166-8.

14. Nowak TS. Synthesis of a stress protein following transient ischemia in the gerbil. J Neurochem 1985;45:1635-41.

15. Hightower LE. Heat shock, stress proteins, chaperones, and proteotoxicity. Cell 1991;66:191-7.

16. Kawagoe J, Abe K, Sato S, Nagano I, Nakanura S, Kogure K. Distributions of heat shock protein (HSP) 70 and heat shock cognate protein (HSC) 70 mRNAs after transient focal ischemia in rat brain. Brain Res 1992;587:195-202.

17. Abe K, Kawagoe J, Aoki M, Kogure K. Dissociation of HSP70 and HSC70 heat shock mRNA induction as an early biochemical marker of ischemic death. Neurosci Lett 1993; 149:165-8.

18. Aoki M, Abe K, Kawagoe J, Sato S, Nakanura S, Kogure K. Temporal profile of the induction of heat shock protein 70 and heat shock cognate protein 70 mRNAs after transient ischemia in gerbil brain. Brain Res 1993;601:185-92.
19. Zivin JA, Reid JL, Saavedra JM, Kopin IJ, Quantitative localization of biogenic amines in the spinal cord. Brain Res 1975;99:293-301.

20. Johnson SH, Kraimer JM, Graeber GM. Effect of flunarizine on neurological recovery and spinal cord blood flow in experimental spinal cord ischemia in rabbits. Stroke 1993;24: 1547-53.

21. Sato S, Abe K, Kawagoe J, Aoki M, Kogure K. Isolation of complementary DNAs for heat shock protein (HSP) 70 and heat shock cognate protein (HSC) 70 genes and the expressions in post-ischemic gerbil brain. Neurol Res 1992;14:37580.

22. Aoki M, Abe K, Kawagoe J, Nakamura S, Kogure K. Acceleration of HSP70 and HSC70 heat shock gene expressions following transient ischemia in the preconditioned gerbil hippocampus. J Cereb Blood Flow Metabol 1993;13: 781-8.

23. Welch WJ, Suhan JP. Cellular and biochemical events in mammalian cells during and recovery from physiological stress. J Cell Biol 1986;103:2035-52.

24. Tuboi N, Ishikawa $M$, Tamura $Y$, et al. Monoclonal antibody specifically reacting against 73-kilodalton heat shock cognate protein: possible expression on mammalian cell surface. Hybridoma 1994;13:373-81.

25. Cheng MK, Robertson C, Grossman RG, Folitz R, Willams $V$. Neurological outcome correlated with spinal evoked potentials in a spinal cord ischemia model. J Neurosurg 1984; 60:786-95.

26. Herold JA, Kron IL, Langenburg SE, et al. Complete prevention of postischemic spinal cord injury by means of regional infusion with hypothermic saline and adenosine. $\mathbf{J}$ Thorac Cardiovase Surg 1994;107:536-42.

27. Zivin JA, DeGirolami U. Spinal cord infarction: a highly reproducible stroke model. Stroke 1980;11:200-2.

28. DeGirolami U, Zinvin JA. Neuropathology of experimental spinal cord ischemia in the rabbit. J Neuropathol Exp Neurol 1982;41:129-49.

29. Jacobs TP, Kempski O, McKinley D, Dutka AJ, Hallenbeck JM, Feuerstein G. Blood flow and vascular permeability during motor dysfunction in a rabbit model of spinal cord ischemia. Stroke 1992;23:367-73.

30. Manzzerra P, Brown IR. Expression of heat shock genes (hsp70) in the rabbit spinal cord: localization of constitutive and hyperthermia-inducible mRNA species. J Neurosci Res 1992;31:606-61. 